\title{
Construction of a cDNA library of the Chinese wild Vitis amurensis under cold stress and analysis of potential hardiness-related expressed sequence tags
}

\author{
J. Zhang ${ }^{1,2}$, N. Liu ${ }^{1,2}$, R. Niu ${ }^{1,2}$, Y. Liu ${ }^{1,2}$, H. Zhai ${ }^{1,2}$, W. Xu ${ }^{1,2}$ and Y. Wang ${ }^{1,2}$ \\ ${ }^{1}$ College of Horticulture, Northwest A\&F University, Yangling, Shaanxi, \\ P.R. China \\ ${ }^{2}$ State Key Laboratory of Crop Stress Biology in Arid Areas, \\ Northwest A\&F University, Yangling, Shaanxi, China \\ Corresponding author: Y. Wang \\ E-mail: wangyj@nwsuaf.edu.cn
}

Genet. Mol. Res. 12 (2): 1182-1193 (2013)

Received July 18, 2012

Accepted October 30, 2012

Published April 12, 2013

DOI http://dx.doi.org/10.4238/2013.April.12.5

\begin{abstract}
A cDNA library of Chinese wild Vitis amurensis, which is the most cold-resistant species in the genus Vitis, was constructed using young leaves of seedlings of the clone Heilongjiang potted and subjected to cold stress. The leaves were harvested at various times after cold stress for total RNA extraction, which was used to generate expressed sequence tags (ESTs). The titer of the original library was $2.67 \times 10^{6} \mathrm{pfu} / \mathrm{mL}$ and the corresponding combination frequency was $98.5 \%$. The test values of the amplified library were $1.53 \times 10^{9} \mathrm{pfu} /$ $\mathrm{mL}$ and $98.2 \%$, respectively. After randomly choosing, cloning and sequencing, 227 ESTs with high quality were obtained and submitted to GenBank database. Using BLASTX, $79.7 \%$ of the ESTs shared homology with known functional DNA sequences and 20.3\% shared significant homology with unknown proteins. Some potential hardinessrelated ESTs were obtained, which were involved in signal transduction,
\end{abstract}


stress inducement, defense reactions, transcription factors, etc. Some functional genes identified from the cDNA library have potential for plant defense. These sequences will be subjected to further researches on hardiness genes and their molecular mechanisms.

Key words: Chinese wild Vitis; Vitis amurensis; Cold hardiness; ESTs; cDNA library

\section{INTRODUCTION}

Grape (Vitis L.) is one of the most important fruit crops in the world, which is widely produced for fresh fruit, juice, raisins, and wines. The main cultivars of grape belong to Vitis vinifera L., which has good fruit quality but poor resistance to disease and cold (He and Luo, 1994; Dalbó et al., 2001). Cold stress is a considerable environmental factor that severely influences the growth and development of plants. Grapevines cultivated in cold regions during winter often suffer various degrees of frost and freeze damage, which subsequently results in financial burden and limits the further development of grape production. Like in many other crops, the utilization of wild cold resistance through genetic crossing and molecular breeding would be an effective strategy to solve the cold injury problem in grape production. China, one of the origins of Vitis (He et al., 1991), owns abundant valuable wild resources of resistance to environmental stress. Vitis amurensis is a critical resistant germplasm resource, especially for cold resistance, where it can resist temperatures as low as $-40^{\circ} \mathrm{C}(\mathrm{He}$ and Luo, 1994). Therefore, it is an important cold-resistant gene source. Gene isolation and cloning is the foundation of the application of genetic engineering, and a cDNA library containing the information from the mRNA of a particular tissue or organism is an effective tool for research on gene structure, function and manipulation (Ying, 2004). Therefore, it is necessary to clone the genomes of plant into cDNA libraries. By differential screening of cDNA libraries, several genes related to low temperature have been identified and characterized in various plant species, such as blueberry (Dhanaraj et al., 2004), Hevea brasiliensis (Cheng et al., 2008), and aspen (Maestrini et al., 2009). In grape, da Silva et al. (2005) constructed several cDNA libraries with different varieties and tissues of European wine-making grapes to investigate gene expression profiles in response to various forms of stress. In a previous study by our group, a cDNA library of powdery mildew resistance-related genes of Chinese wild V. pseudoreticulata (Xu et al., 2009) and two subtractive hybridization libraries (SSHs) of Chinese wild V. pseudoreticulata resistant to downy mildew (Zhang et al., 2009) and powdery mildew (Shi et al., 2010) were constructed. These previous studies mainly focused on the differentially expressed genes involved in grape-pathogen interactions. However, limited information could be obtained on the differentially expressed genes related to cold resistance in Chinese wild Vitis species. We report here our efforts in constructing and characterizing a $V$. amurensis cold resistance cDNA library. The potted Chinese wild $V$. amurensis clone Heilongjiang Seedlings were treated by cold stress and a cDNA library was then constructed using SMART ${ }^{\mathrm{TM}}$ techniques to obtain potential cold resistance-related expressed sequence tags (EST). After analyzing their types, we carried out a further analysis of 4 genes from the library. Such resources will provide basic information for further cloning of complete hardiness-related genes and molecular breeding studies. 


\section{MATERIAL AND METHODS}

\section{Plant materials and treatments}

Chinese wild $V$. amurensis clone Heilongjiang Seedling, which is highly resistant to cold stress and kept in grape germplasm repository at the Northwest A\&F University, Yangling Shaanxi, People's Republic of China, was used in this study. In January 2010, one-year-old branches were cut from plants for cuttage, soaked for $2 \mathrm{~h}$ in the transplantone, propagated and cultivated in a greenhouse (temperature $25^{\circ} \mathrm{C}$, light $2000 \mathrm{~lx}$ ). In July, well-grown and healthy potted plants were selected for further cold stress and total RNA isolation.

\section{Isolation and purification of total RNA}

Heilongjiang Seedling-potted plants were placed in a refrigerator at $4^{\circ} \mathrm{C}$ for $0,2,6$, 12,24 , and $48 \mathrm{~h}$. After cold stress, total RNA was extracted with liquid nitrogen from young leaves of various materials, using the improved SDS/phenol method (Zhang et al., 2003). Through purification of total RNA, a balanced mixture was used to determine integrity by $1.1 \%$ agarose gel electrophoresis and both purity and concentration with the NanoDrop ND1000 UV-Vis Spectrophotometer (Gene Co. Ltd., Hong Kong, China).

\section{Library construction}

According to the instructions of the SMART ${ }^{\mathrm{TM}}$ cDNA Library Construction kit (Clontech, USA), a balanced mixture of total RNA (approximately $1.0 \mu \mathrm{g}$ ) served as template for reverse transcription and long distance-PCR, and the distribution range was then tested by $1.1 \%$ agarose gel electrophoresis. After SfiI enzyme cutting and CHROMA SPIN-400 column chromatography, fragments over $500 \mathrm{bp}$ were collected to be ligated with $\lambda$ TripLEx 2 and packaged with MaxPlax ${ }^{\mathrm{TM}}$ Lambda Packaging Extract (Epicentre Technologies, USA). The original library was thus obtained and could be used to form an amplified library according to instructions. After the addition of DMSO (final concentration of $7 \%$ ), the amplified library was kept at $-80^{\circ} \mathrm{C}$.

\section{Identification of library quality}

A $10-\mu \mathrm{L}$ aliquot of dilution (library: $1 \mathrm{X}$ lambda dilution buffer $=1: 100$ ) was mixed with $200 \mu \mathrm{L}$ overnight culture of XL1-Blue bacterium solution at $37^{\circ} \mathrm{C}$ for $30 \mathrm{~min}$. After quickly adding $3 \mathrm{~mL}$ top medium, $50 \mu \mathrm{L} 100 \mathrm{mM}$ IPTG and $50 \mu \mathrm{L} 100 \mathrm{mM}$ X-Gal and mixing well, the mixture was poured on LB solid agar plates, preheated to $37^{\circ} \mathrm{C}$, and the plates then incubated overnight at $37^{\circ} \mathrm{C}$. Finally, the titer and the recombination frequency of the library were calculated by the number of blue and white plaques: library titer $\mathrm{P}(\mathrm{pfu} / \mathrm{mL})=$ number of plaques $\mathrm{x}$ dilution factor $\times 10^{3} /$ volume of phage plates $(\mu \mathrm{L})$, and recombination frequency $(\%)=$ number of white plaques / total number of plaques.

\section{EST sequencing}

According to the sequences of two ends of the $\lambda$ phage vector, forward primer was 
designed as 5'-TCC GAG ATC TGG ACG AGC-3' and the corresponding reverse primer was designed as 5'-TAA TAC GAC TCA CTA TAG GG-3'.

PCR procedures were carried out as follows: initial denaturation at $94^{\circ} \mathrm{C}$ for $5 \mathrm{~min}$; $94^{\circ} \mathrm{C}$ for $1 \mathrm{~min}, 55^{\circ} \mathrm{C}$ for $1 \mathrm{~min}$ and $72^{\circ} \mathrm{C}$ for $2 \mathrm{~min}(35$ recycles in total), and a primer extension at $72^{\circ} \mathrm{C}$ for $10 \mathrm{~min}$. After amplification by plasmid PCR and identification by positive clone screening, suspected strains were combined with the same amount of $30 \%$ glycerin and then sent to Shanghai Meiji Company (China) for sequencing.

\section{Homology comparisons}

Each edited EST was translated in all six reading frames and compared with the non-redundant database at the National Center for Biotechnology (NCBI) using the BLASTX program, which compares translated nucleotide sequences with protein sequences. Default BLAST parameter values were used, except for the following settings: expect $=1$, alignments $=10$, and descriptions $=10$. Sequences that returned no significant similarity were again compared using BLASTN, which compares nucleotide sequence with nucleotide sequences, with expect $=1$, alignments $=10$, and descriptions $=10$. Homologies to negative reading frames were disregarded, except in clones with inserts in the reverse orientation. Putative identifications for the ESTs were assigned based on the results of the BLAST searches and, in some cases, with information contained in related abstracts in PubMed. The non-redundant set of $V$. amurensis clone Heilongjiang Seedling ESTs was deposited in GenBank.

\section{Analysis of ESTs}

cDNA sequences generated from each cDNA clone were carefully edited to remove the flanking vector sequence and the low-quality sequences (http://www.ncbi.nlm.nih.gov/ VecScreen/VecScreen.html). ESTs longer than $150 \mathrm{bp}$ and containing no more than $4 \%$ ambiguity were considered useful for data analysis. Using the BLAST service, at NCBI (http:// www.ncbi.nlm.nih.gov), sequences were searched against the protein and nucleic acid databases. Sequence similarities identified by the BLAST programs were considered to be statistically significant at an E-value of $\leq 10^{5}$.

\section{Quantitative real-time PCR}

In July 2010, well-grown and healthy potted plants were placed in a refrigerator at $4^{\circ} \mathrm{C}$ for $0,2,6,12,24$, and $48 \mathrm{~h}$. Young leaves, stems and fibrous roots were collected, immediately immersed in liquid nitrogen, and stored at $-80^{\circ} \mathrm{C}$. Using total RNA as template, onestep reverse transcription PCR was performed with M-MLV reverse transcriptase according to manufacturer instructions (Promega, USA).

The expression patterns of four genes including early-responsive to dehydration gene $(E R D)$, dehydration-responsive gene (RD22), chitinase $(C H)$, and $\beta$-glucanase $(G L U)$ in each tissue were quantified by quantitative real-time PCR using primer, with 18S rRNA serving as the internal control (Table 1). First-strand cDNA was synthesized from $1 \mu \mathrm{L}$ DNase-treated total RNA; qRT-PCR was conducted using SYBR ${ }^{\circledR}$ Premix Ex Taq ${ }^{\mathrm{TM}}$ II (Takara Biotechnology 
Co. Ltd., Dalian, China) on an IQ5 real-time PCR detection system (Bio-Rad, Hercules, CA, USA). Each reaction was done in triplicates with a reaction volume of $25 \mu \mathrm{L}$. Cycling parameters were $95^{\circ} \mathrm{C}$ for $3 \mathrm{~min}$ and 35 cycles of $95^{\circ} \mathrm{C}$ for $30 \mathrm{~s}$ and $58^{\circ} \mathrm{C}$ for $1 \mathrm{~min}$.

Table 1. Pair of primers of cold resistance-related genes and reference gene for quantitative RT-PCR.

\begin{tabular}{lll}
\hline $\begin{array}{l}\text { Cold resistance-related } \\
\text { genes/reference gene }\end{array}$ & Upstream primer & Downstream primer \\
\hline$E R D$ & 5'-ATGGCTATGGAGGTAATTTCACGTAC-3' & 5'-TTACCGCGGCTGCTGAATCG-3' \\
$G L U$ & 5'-TAGGGAGTCGTTTCAGATAAGCACAA-3' & 5'-ATTGACAAAAGAAGGGTGTAAGAGCA-3' \\
$R D 22$ & 5'-GTTTTACTGCCACAAGACTCAGACCA-3' & 5'-GGAATAATATGATGGGGTTTGAAGTA-3' \\
$C H$ & 5'-AACTACTGTGATTCAAGCAATACCCA-3' & 5'-TGCAGTAGTCCTTGTAATACTGAACG-3' \\
$18 \mathrm{~S}$ rRNA & 5'-TGGCCTTCGGGATCGGAGTAA-3' & 5'-ATCCCTGGTCGGCATCGTTTAT-3' \\
\hline
\end{tabular}

\section{RESULTS}

\section{Extraction of total RNA}

Total RNA from young leaves of $V$. amurensis clone Heilongjiang Seedling showed two bright bands (28S and $18 \mathrm{~S}$ ) with a specific ratio (Figure 1 ). The purity test by ultraviolet spectral analysis indicated that $\mathrm{A}_{260} / \mathrm{A}_{280}$ varied between 1.8 and 2.2, which meant that the extracted RNA was suitable to construct the library.

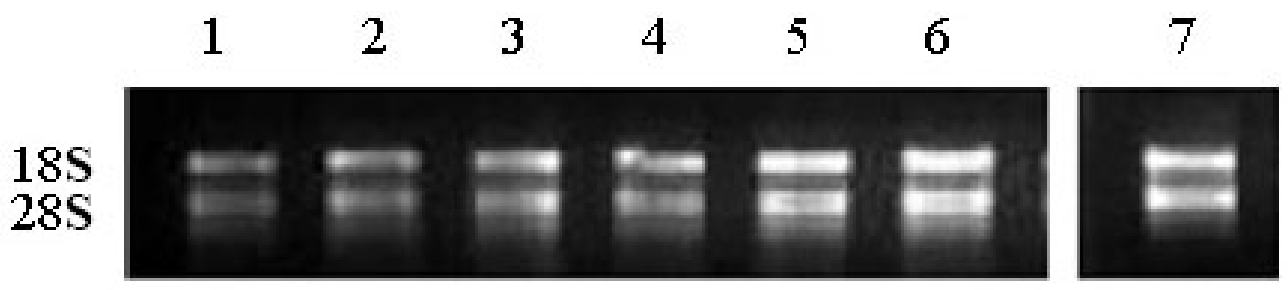

Figure 1. Extraction of total RNA of materials in different conditions and the RNA mixture. Lanes 1 to $6=$ total RNA extracted from materials with $0,2,6,12,24$, and $48 \mathrm{~h}$ cold stress, respectively; lane $7=$ RNA mixture.

\section{Library construction and quality identification}

Double-stranded cDNA was synthesized by reverse transcription and long distancePCR of purified total RNA. As shown in Figure 2, double-stranded cDNA appeared as a smear ranging from 500 to $3000 \mathrm{bp}$. Also, there were abundant bands at $1000 \mathrm{bp}$. After SfiI enzyme cutting and CHROMA SPIN-400 column chromatography, cDNA fragments over $500 \mathrm{bp}$ in tubes 6 to 9 were mixed (Figure 3).

The titer of the original library was $2.67 \times 10^{6} \mathrm{pfu} / \mathrm{mL}$ and the recombination frequency was $98.5 \%$. The corresponding values of the amplified library were $1.53 \times 10^{9} \mathrm{pfu} / \mathrm{mL}$ and $98.2 \%$, respectively. The cDNA insert fragments distributed between 500 and $2000 \mathrm{bp}$, the majority of which were about 1000 bp (Figure 4). 


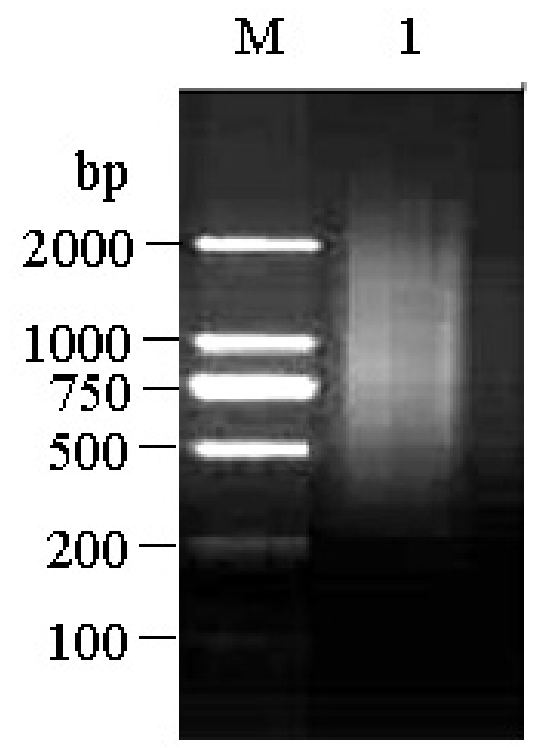

Figure 2. Double-strand cDNA. Lane $M=$ DL2000 marker; lane $1=$ double-stranded cDNA.

\section{$\begin{array}{lllllllllllllllll}1 & 2 & 3 & 4 & 5 & 6 & 7 & 8 & 9 & 10 & 11 & 12 & 13 & 14 & 15 & 16 & \mathrm{M}\end{array}$}

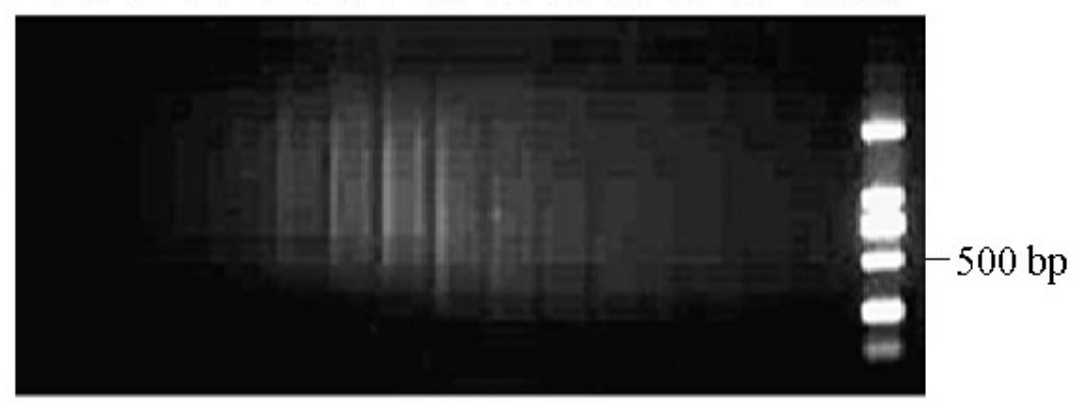

Figure 3. Recycle of long distance-PCR by CHROMA SPIN-400 column chromatography. Lanes 1 to $16=\mathrm{cDNA}$; lane $M=$ DL2000 marker.

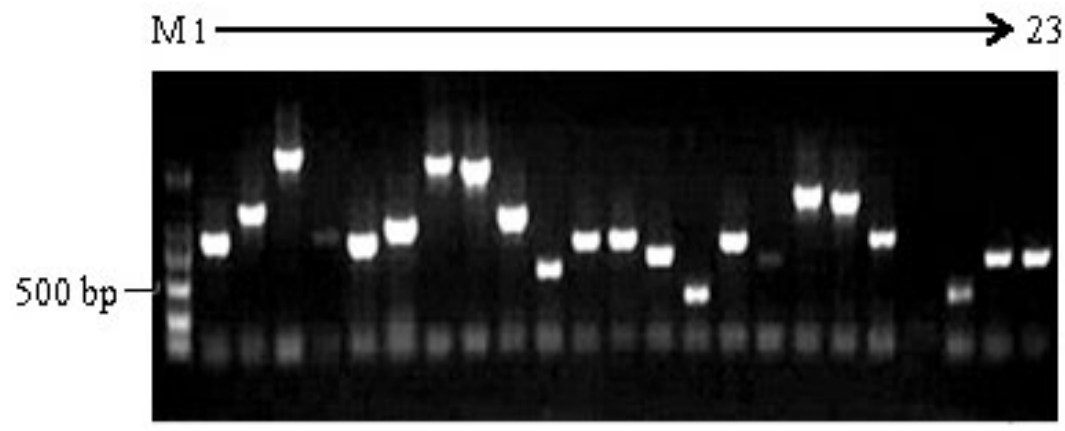

Figure 4. PCR analyses of partial cDNA insert fragments. Lane $M=$ DL2000 marker; lanes 1 to $23=$ single colony. 


\section{Sequencing of ESTs and sequence analysis}

Insert fragments over $400 \mathrm{bp}$ were sent for sequencing. After identification and removal of flanking vector sequences by the VecScreen program in NCBI, all sequences were further checked and the repeated sequences were removed, and then the remainders were spliced by multiple sequence alignment in DNASTAR. We obtained 227 non-repetitive sequences, which were submitted to GenBank with accession Nos. JG294234-JG294243, JG392010-JG392092, and JK006548-JK006681.

Comparing with the protein database of GenBank using the BLASTX software, we found that $181(79.7 \%)$ sequences shared homology with known functional DNA sequences and that $46(20.3 \%)$ sequences shared significant homology with unknown proteins. After classification of those known functional ESTs, some of them were found to be constitutive genes mainly involved in primary metabolism, protein synthesis, etc. According to published studies on stress resistance in plants, there is more specific information about these ESTs, where 38 of them were involved in stress responses in which defenserelated proteins are produced, such as chitinase, pathogenesis-related protein 10 (PR10), immunophilin, abscisic stress ripening protein, salt tolerance protein, and metallothionein, among others. Some were related to signal transduction, for example, calmodulin and $\mathrm{G}$ protein. Some were stress-inducible proteins, such as the ERD protein, heat stable proteins, polyubiquitin, ubiquitin-related proteins, F-box family, DnaJ protein, hypersensitive-induced reaction proteins, and ozone-responsive stress-related proteins. There were also transcription factors such as MYB49, AP2, RD22 protein, etc. (Table 2). All the above factors may play a certain role in plant resistance to low temperature.

\section{Analysis of quantitative real-time PCR}

qRT-PCR showed that the expression patterns in mRNA levels of the GLU, RD22, $E R D$, and $C H$ genes compared to $18 \mathrm{~S}$ RNA in young leaves, stems and fibrous root displayed different changes after the $4^{\circ} \mathrm{C}$ treatment for $0,2,6,12,24$, and $48 \mathrm{~h}$. Specifically, these four genes all displayed significant changes after cold treatment, which peaked at 12 $\mathrm{h}$, in which the maximum induction was $\operatorname{VaERD}$ (ERD from V. amurensis was called VaERD, the same as $\mathrm{VaGLU}, \mathrm{VaRD}$ and $\mathrm{VaCH}$ ) (Figure 5A). Although there was differential expression of these four genes in roots, VaERD and VaRD22 reached the highest level at $2 \mathrm{~h}$, and $\mathrm{VaGLU}$ and $\mathrm{VaCH}$ peaked at $6 \mathrm{~h}$ (Figure 5B). However, expression was repressed after cold treatment in stems (Figure 5C), demonstrating that these four genes were involved in the mechanism of cold resistance.

\section{DISCUSSION}

V. amurensis originated from Northeast China, North China, North Korea, and the far east of the former Soviet Union (Shen, 1985), and belongs to the most resistant grapevines with vines resistant to $-40^{\circ} \mathrm{C}$ and root system resistant from $-14^{\circ}$ to $-16^{\circ} \mathrm{C}$ (He and Luo, 1994), so the clone Heilongjiang Seedling of $V$. amurensis was chosen as the material to construct a cold stress-induced cDNA library. Construction of the cDNA library and analysis of ESTs in this study identified a range of genes likely to be involved in defense against abiotic stresses, 


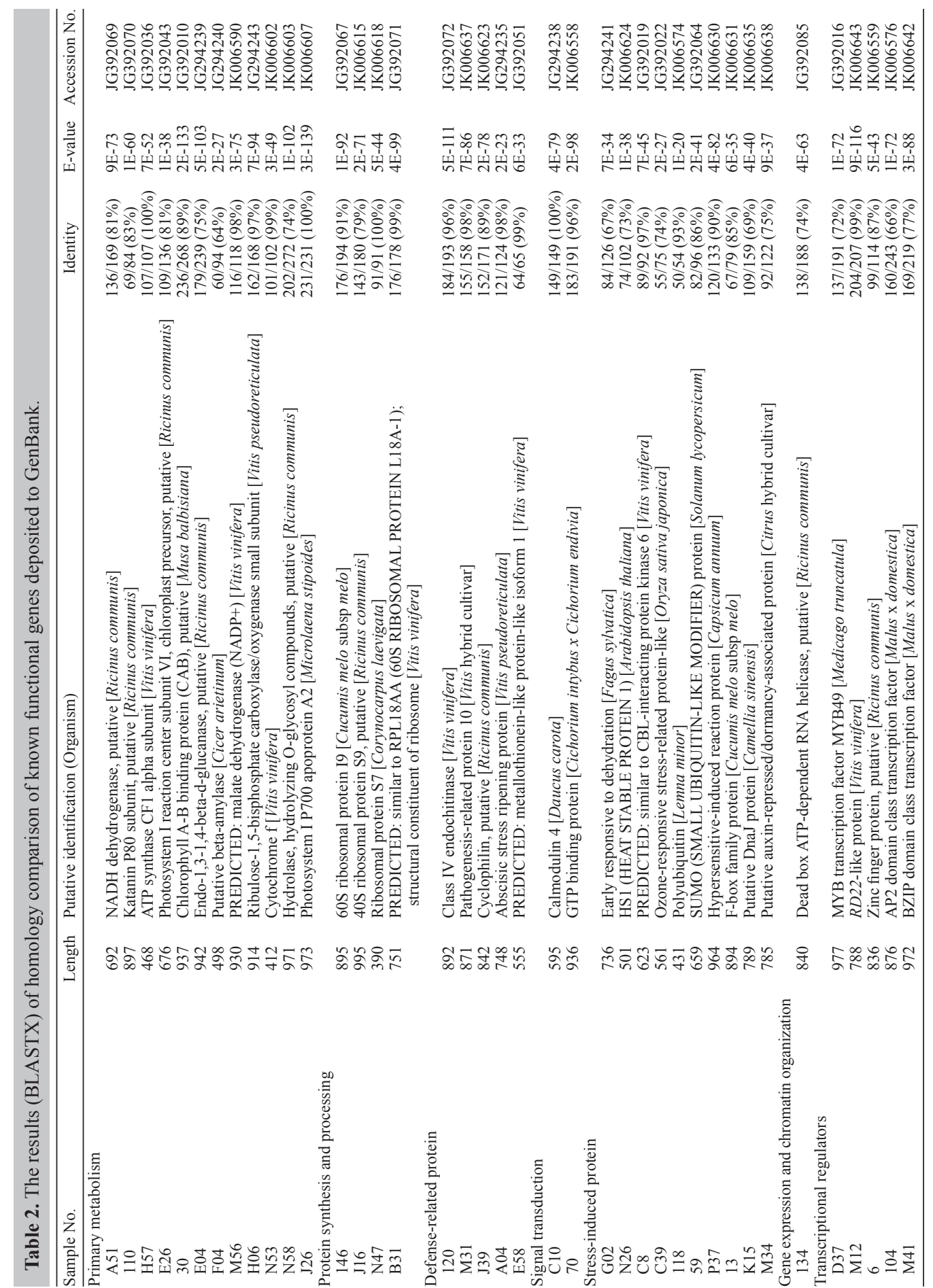



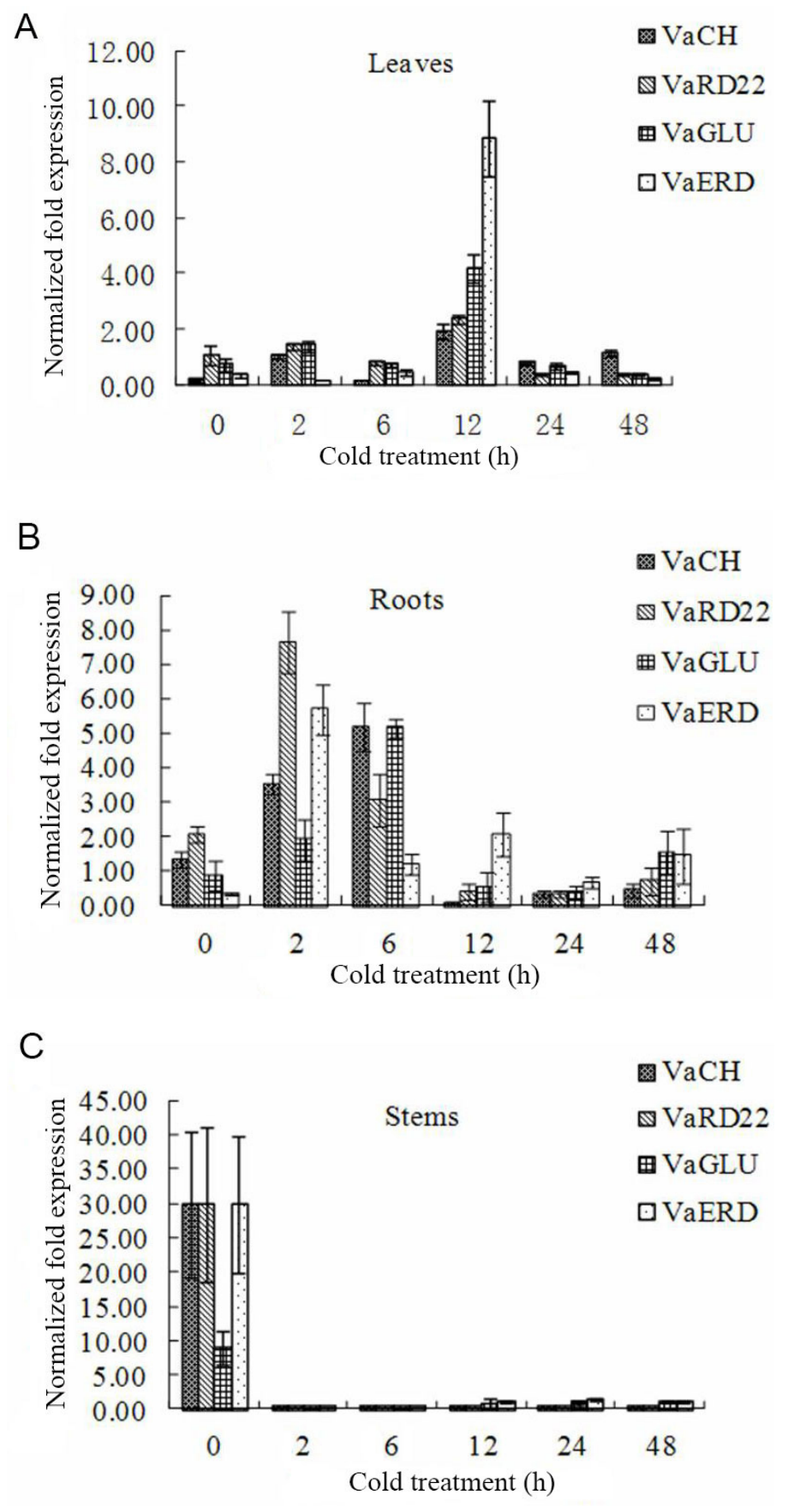

Figure 5. Expression patterns of genes including early-responsive to dehydration gene $(E R D)$, dehydrationresponsive gene $(\mathrm{RD} 22)$, chitinase $(\mathrm{CH})$, and $\beta$-glucanase $(G L U)$ in different parts of Heilongjiang Seedling and with different times of treatment. 18S rRNA was used as internal control. Va $=$ Vitis amurensis. 
and provided some insight into the complex phenotype of cold resistance in Chinese wild Vitis species. By isolating cDNAs from the $V$. amurensis clone Heilongjiang Seedling in response to cold stress, we isolated a number of ESTs. This study aimed to enrich the cDNA library for the presence of cold-related sequences so that a number of ESTs involved in low-temperature defense responses could be identified. The gene expression profiles of several candidate ESTs, including $\mathrm{VaERD}, \mathrm{VaRD} 22, \mathrm{VaCH}$, and $\mathrm{VaGLU}$, were further analyzed (Figure 5), and the results are consistent with previous studies on these genes in plant responses to cold stress.

The reaction to cold stress in plants is a very complicated process, where the coldresponsive genes whose expression is altered are involved in the metabolism and structure change of lipids, proteins and carbohydrates. In a low-temperature environment, the expression level of related protein tends to increase, such as starch degradation enzyme and $\beta$-amylase (Fowler and Thomashow, 2002). Actually, the accumulation of saccharides in cells can protect plants to some extent, by improving the cell's water retention ability or producing some substances and energy to protect essential cell components, including genetic material and biomembranes. It has been well-documented that under cold stress, the expression levels of many energy-producing proteins tend to increase (Maestrini et al., 2009), thus guaranteeing normal physiological and biochemical processes by providing enough energy for hardiness.

In our constructed cDNA library, hardiness-related genes were categorized according to signal transduction, transcriptional regulators and cold defense. For example, signal $\mathrm{Ca}^{2+}-$ related genes and genes encoding $G$ protein may be related to cold resistance in Heilongjiang Seedling. In the early phase of cold hardening, calmodulin is likely to function as a messenger (Wang and Guo, 2003). Under low-temperature or short-day conditions, etc., membrane fluidity would change and a large quantity of $\mathrm{Ca}^{2+}$ would be released from cellular calcium stores to the cytoplasm through $\mathrm{Ca}$ channels in the membrane, raising the cytoplasmic concentration of free $\mathrm{Ca}^{2+}$ dramatically and rapidly (Wang and Guo, 2003). This would probably lead to signal cascades and increase the expression of hardiness genes. Previous studies have indicated that under cold stress, Populus increases its expression levels of $\mathrm{Ca}^{2+}$ or CaM in plants (Dhanaraj et al., 2004). Besides, G protein has GTPase activity and can function as a signal transducer or molecular switch in signal transduction pathways. It has been proved that $\mathrm{G}$ protein is involved in photostimulation signal transduction, regulating $\mathrm{K}^{+}$channels, phytohormone signal transduction or some defense reactions against pathogens (Nogueira et al., 2003). Until now, the study of mechanisms of plant cell signal transduction is still limited. Whether G protein is concerned with hardiness reactions still needs to be further investigated.

Ubiquitin ligases, MYB transcription factor and BURP dehydration-responsive gene $R D 22$, for example, are known to be concerned with plant cold resistance (Nagaoka and Takano, 2003; Dhanaraj et al., 2004; Todgham et al., 2007). In this study, one of the ESTs obtained showed high homology with ubiquitin ligase (93\%). Ubiquitin, involved in reactions responsive to drought stress, cold stress, salt stress and heavy metal ion stress, can degrade impaired protein under stress through the ubiquitin pathway to guarantee normal metabolism. Three E3 ubiquitin ligase-encoding genes in poplars under $4^{\circ} \mathrm{C}$ conditions were identified by Maestrini et al. (2009), who also found that the expression level of genes encoding E3 ubiquitin ligase involved in ubiquitination, E2 ubiquitin-binding enzyme, ubiquitin $\mathrm{COOH}$-terminal hydrolase, and polyubiquitination protein increased under cold stress. Nogueira et al. (2003) proved that five encoding ESTs of polyubiquitination protein in sugarcane were induced to express under cold stress. The process of protein degradation mediated by ubiquitin in Arabidopsis is critical in the regulation of ICE1 regulator and thus regulates gene transcription 
in hardiness reactions (Zhu et al., 2007). MYB is believed to regulate the response to drought stress, cold stress, salt stress, nutrient deficiency, and other forms of biotic stress (Nagaoka and Takano, 2003; Denekamp and Smeekens, 2003). In wheat, three types of TaMyb2 regulators were separated. They were all expressed in response to various abiotic stresses, including osmotic stress, high-salt stress, cold stress, and exogenous ABA induction (Jia et al., 2008). Su et al. (2010) reported that MYBS3 is involved in hardiness signal transcription in wheat. All of the above studies suggest that the $M Y B$ family has a very close relation with abiotic stress and is also involved in plant cold resistance.

Furthermore, we found some stress-related genes in the library, one of which was $E R D$, which can rapidly respond to drought and other abiotic stress. Until now, $16 E R D$ genes have been isolated from Arabidopsis, some of which can respond to various stress signals, such as cold stress, salt stress, aging, ABA, etc. Previous studies have suggested that ERD6 encodes a sugar transporter, and the ERD6 protein has 12 putative transmembrane domains and a central hydrophilic region. The expression of the ERD6 gene was induced not only by dehydration but also by cold treatment (Kiyosue et al., 1998). The excessive expression of ERD15 would weaken plants' sensitivity to ABA, thus weakening plants' cold resistance and drought tolerance (Kariola et al., 2006). ERD genes are still not fully understood in other plants, especially with regard to grapevine hardiness. In our study, ERD genes were identified as strong candidates for expression in $V$. amurensis as a defense response to low temperature. Another gene, BURP dehydration-responsive gene $R D 22$, is induced indirectly by ABA content under adverse environmental stresses. In autumn, the content of ABA in buds of some perennial woody plants is relatively high and the moisture content is relatively low; in winter, ABA levels tends to decrease. Dhanaraj et al. (2004) suggested that the expression level of $R D 22$ in blueberry cDNA library was influenced indirectly by the content of ABA or water in buds when under cold stress. According to RT-PCR, the occurrence of $R D 22$ in the Heilongjiang Seedling cDNA library was a response to cold stress. A better understanding of $R D 22$ might enable us to manipulate various aspects of these cold-resistant organisms. $\mathrm{CH}$ and $G L U$, representing pathogenesis-related protein genes were also found in our library. It has been postulated that plant chitinases and $\beta$-glucanases play an important role in defense mechanisms involving chitin in cell walls (Nasser et al., 1990). Both of these two genes belong to $P R$ genes. Zhu et al. (1994) suggested that chitinases and glucanases can be part of an effective approach to engineering enhanced crop protection against fungal disease. However, our study supposed that chitinases and $\beta$-glucanases also participate in cold defense mechanisms in grapevine. Although these ESTs discussed above were expressed in resistant $V$. amurensis leaf and root tissue, further investigation is still required to conclusively determine the function of these genes in Chinese wild Vitis plants. In addition, this is the first report of the analysis of ESTs from $V$. amurensis in a cDNA library, and the information may has significant applications in future studies on gene expression, mapping and genetic manipulation in $V$. amurensis.

\section{ACKNOWLEDGMENTS}

Research supported by the Earmarked Fund for China Agriculture Research System (Grant \#CARS-30-yz-7) and the Sci-Tech Department of Shaanxi Province of the People's Republic of China (Shaanxi Province Sci-Tech Key Project; Grant \#2011K02-10). 


\section{REFERENCES}

Cheng H, Cai HB and Huang HS (2008). Construction of full-length cDNA library in rubber tree under cold stress. Chin. J. Trop. Crops 29: 410-414.

da Silva FG, Iandolino A, Al-Kayal F, Bohlmann MC, et al. (2005). Characterizing the grape transcriptome. Analysis of expressed sequence tags from multiple Vitis species and development of a compendium of gene expression during berry development. Plant Physiol. 139: 574-597.

Dalbó MA, Ye GN, Weeden NF, Wilcox WF, et al. (2001). Marker-assisted selection for powdery mildew resistance in grapes. J. Am. Soc. Hortic. Sci. 126: 83-89.

Denekamp M and Smeekens SC (2003). Integration of wounding and osmotic stress signals determines the expression of the AtMYB102 transcription factor gene. Plant Physiol. 132: 1415-1423.

Dhanaraj AL, Slovin JP and Rowland LJ (2004). Analysis of gene expression associated with cold acclimation in blueberry floral buds using expressed sequence tags. Plant Sci. 166: 863-872.

Fowler S and Thomashow MF (2002). Arabidopsis transcriptome profiling indicates that multiple regulatory pathways are activated during cold acclimation in addition to the CBF cold response pathway. Plant Cell 14: 1675-1690.

He PC and Luo GG (1994). Grape Science. China Agriculture Press, Beijing.

He PC, Wang YJ, Wang GY, Ren ZB, et al. (1991). The studies on the disease resistance of Chinese wild Vitis species. Sci. Agric. Sin. 24: 50-56.

Jia DS, Mao XG, Wu RL, Zhang XK, et al. (2008). Cloning and expression of transcription factor TaMyb2s in wheat. Acta Agronom. Sin. 34: 1323-1329.

Kariola T, Brader G, Helenius E, Li J, et al. (2006). EARLY RESPONSIVE TO DEHYDRATION 15, a negative regulator of abscisic acid responses in Arabidopsis. Plant Physiol. 142: 1559-1573.

Kiyosue T, Abe H, Yamaguchi-Shinozaki K and Shinozaki K (1998). ERD6, a cDNA clone for an early dehydrationinduced gene of Arabidopsis, encodes a putative sugar transporter. Biochim. Biophys. Acta 1370: 187-191.

Maestrini P, Cavallini A, Rizzo M, Giordani T, et al. (2009). Isolation and expression analysis of low temperature-induced genes in white poplar (Populus alba). J. Plant Physiol. 166: 1544-1556.

Nagaoka S and Takano T (2003). Salt tolerance-related protein STO binds to a $M y b$ transcription factor homologue and confers salt tolerance in Arabidopsis. J Exp. Bot. 54: 2231-2237.

Nasser W, de Tapia M and Burkard G (1990). Maize pathogenesis-related proteins: characterization and cellular distribution of 1,3- $\beta$-glucanases and chitinases induced by brome mosaic virus infection or mercuric chloride treatment. Physiol. Mol. Plant Pathol. 36: 1-14.

Nogueira FTS, De Rosa V Jr, Menossi M, Ulian EC, et al. (2003). RNA expression profiles and data mining of sugarcane response to low temperature. Plant Physiol. 132: 1811-1824.

Shen DX (1985). Fruit Trees Breeding. China Agriculture Press, Beijing.

Shi JL, Wang YJ, Zhu ZG and Zhang CH (2010). The EST analysis of a suppressive subtraction cDNA library of Chinese wild Vitis pseudoreticulata inoculated with Uncinula necator. Agric. Sci. China 9: 233-241.

Su CF, Wang YC, Hsieh TH, Lu CA, et al. (2010). A novel MYBS3-dependent pathway confers cold tolerance in rice. Plant Physiol. 153: 145-158.

Todgham AE, Hoaglund EA and Hofmann GE (2007). Is cold the new hot? Elevated ubiquitin-conjugated protein levels in tissues of Antarctic fish as evidence for cold-denaturation of proteins in vivo. J. Comp. Physiol. B 177: 857-866.

Wang GL and Guo ZF (2003). The progress of researches on molecular mechanism of chilling tolerance in plants. Chin. Bull. Bot. 20: 671-679.

Xu Y, Zhu Z, Xiao Y and Wang Y (2009). Construction of a cDNA library of Vitis pseudoreticulata native to China inoculated with Uncinula necator and the analysis of potential defence-related expressed sequence tags (ESTs). $S$. Afr. J. Enol. Vitic. 30: 65-71.

Ying SY (2004). Complementary DNA libraries: an overview. Mol. Biotechnol. 27: 245-252.

Zhang JJ, Wang YJ and Wang XP (2003). An improved method for rapidly extracting total RNA from Vitis. J. Fruit Sci. 20: $178-181$.

Zhang JW, Wang YJ, Zhu ZG, Wang PY, et al. (2009). Construction and preliminary analysis of the SSH library of Chinese wild Vitis pseudoretioulata resistance to downy mildew. Sci. Agric. Sin. 42: 960-966.

Zhu Q, Maher EA, Masoud S, Dixon RA, et al. (1994). Enhanced protection against fungal attack by constitutive coexpression of chitinase and glucanase genes in transgenic tobacco. Nat. Biotechnol. 12: 807-812.

Zhu J, Dong CH and Zhu JK (2007). Interplay between cold-responsive gene regulation, metabolism and RNA processing during plant cold acclimation. Curr. Opin. Plant Biol. 10: 290-295. 